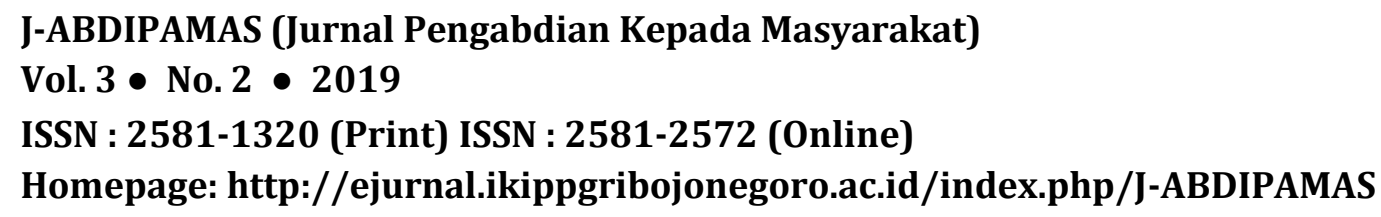

ISSN : 2581-1320 (Print) ISSN : 2581-2572 (Online)

Homepage: http://ejurnal.ikippgribojonegoro.ac.id/index.php/J-ABDIPAMAS

\title{
PELATIHAN PEMBUATAN BAHAN AJAR BAGI GURU PPKn MTS DI KABUPATEN PONOROGO
}

\author{
Ambiro Puji Asmaroini' ${ }^{1}$, Ardhana Januar Mahardhani ${ }^{2}$ \\ 1Universitas Muhammadiyah Ponorogo, Email: ambirop@gmail.com \\ 2Universitas Muhammadiyah Ponorogo,Email: ardhana@umpo.ac.id
}

\begin{abstract}
Todays, PPKn teachers in MTs in Ponorogo district need information and guidance to be able to make modules as teaching materials. The module is useful for teaching and learning activities in class. The purpose of this activity is that PPKn teachers in MTs in Kabupaten Ponorogo are able to: 1) Understand the material about modules, 2) Understand the procedures for preparing modules, and 3) Arrange / Make PPKn modules for SMP / MTs. this activity uses training methods and practice in making modules, lectures and frequently asked questions. From 13 participants producing PPKn modules for SMP / MTs grade 7 and 8. 12 participants were able to complete 1 chapter module, while 1 other participant was able to complete 1 module for grade 8 SMP / MTs by Mrs. Sri Harmanti, S.Pd from State MTs 3 Ponorogo. Currently the book is in the process of revision and maintenance of the ISBN.
\end{abstract}

Keywords: modules, PPKN Teacher, teaching materials

\begin{abstract}
ABSTRAK
Saat ini, guru-guru PPKn di MTs kabupaten Ponorogo membutuhkan informasi dan panduan agar mampu membuat modul sebagai bahan ajar. Modul tersebut berguna bagi kegiatan belajar mengajar di kelas. Tujuan kegiatan ini agar guru-guru PPKn di MTs Kabupaten Ponorogo mampu: 1) Memahami materi tentang modul, 2) Memahami tata cara penyusunan modul, dan 3) Menyusun/Membuat modul PPKn untuk SMP/MTs. kegiatan ini menggunakan metode pelatihan dan praktik dalam membuat modul, ceramah dan tanya jawab. Dari 13 peserta menghasilkan modul PPKn untuk SMP/MTs kelas 7 dan 8. 12 peserta mampu menyelesaikan 1 bab modul, sedangkan 1 peserta lain mampu menyelesaikan 1 modul kelas 8 SMP/MTs oleh Ibu Sri Harmanti, S.Pd dari MTs Negeri 3 Ponorogo. Saat ini buku tersebut sedang proses revisi dan pengurusan ISBN.
\end{abstract}

Kata kunci: bahan ajar modul, guru PPKn

\section{PENDAHULUAN}

Guru PPKn MTs di Kabupaten Ponorogo, terjalin komunikasi melalui sebuah perkumpulan yaitu Musyawarah Guru Mata Pelajaran (MGMP) PPKn. Direktorat Jenderal Peningkatan Mutu Pendidik dan Tenaga Kependidikan (2010: iv) menegaskan bahwa MGMP (Musyawarah Guru Mata Pelajaran) merupakan wadah kegiatan profesional bagi para guru mata pelajaran yang sama pada jenjang SMP/MTs/SMPLB, SMA/MA/SMALB, dan SMK/MAK di tingkat kabupaten/kota yang terdiri dari sejumlah guru dari sejumlah sekolah. MGMP PPKn MTs Kabupaten Ponorogo rutin melaksanakan 
kegiatan per semester di MTs Negeri 1 Ngunut yang beralamatkan di Jalan Sukowati Nomor 90, Desa Ngunut, Kecamatan Babadan Kabupaten Ponorogo.

Adapun tujuan dari KKG/MGMP menurut Direktorat Profesi Pendidik (2008: 4) adalah sebagai berikut:

1. Memperluas wawasan dan pengetahuan guru dalam berbagai hal, khususnya penguasaan substansi materi pembelajaran, penyusunan silabus, penyusunan bahanbahan pembelajaran, strategi pembelajaran, metode pembelajaran, memaksimalkan pemakaian sarana/prasarana belajar, memanfaatkan sumber belajar, dsb.

2. Memberi kesempatan kepada anggota kelompok kerja atau musyawarah kerja untuk berbagi pengalaman serta saling memberikan bantuan dan umpan balik.

3. Meningkatkan pengetahuan dan keterampilan, serta mengadopsi pendekatan pembaharuan dalam pembelajaran yang lebih profesional bagi peserta kelompok kerja atau musyawarah kerja.

4. Memberdayakan dan membantu anggota kelompok kerja dalam melaksanakan tugastugas pembelajaran di sekolah.

5. Mengubah budaya kerja anggota kelompok kerja atau musyawarah kerja (meningkatkan pengetahuan, kompetensi dan kinerja) dan mengembangkan profesionalisme guru melalui kegiatan-kegiatan pengembangan profesionalisme di tingkat KKG/MGMP.

6. Meningkatkan mutu proses pendidikan dan pembelajaran yang tercermin dari peningkatan hasil belajar peserta didik.

7. Meningkatkan kompetensi guru melalui kegiatan-kegiatan di tingkat KKG/MGMP.

Berdasarkan tujuan tersebut, dalam rangka memperluas wawasan guru PPKn dalam kegiatan pembelajaran di kelas, diadakannya kegiatan pelatihan pembuatan bahan ajar berupa modul. Modul merupakan bahan ajar cetak yang dirancang untuk dapat dipelajari secara mandiri oleh peserta pembelajaran (Direktorat Tenaga Kependidikan, 2008: 3). Dengan adanya modul akan memudahan guru dan siswa dalam kegiatan pembelajaran di kelas.

Selama ini, dibutuhkan keterampilan guru dalam membuat modul. Namun tidak semua guru mampu membuat modul dalam pembelajaran mata pelajaran PPKn. Guru juga belum memiliki panduan dalam pembuatan modul.

\section{METODE PELAKSANAAN}

Guru PPKn MTs Kabupaten Ponorogo yang tergabung dalam MGMP PPKn MTs Kabupaten Ponorogo masih mendapatkan kesulitan dalam menyusun modul PPKn. Hal ini telah disampaikan oleh ibu Sri Harmanti selaku ketua MGMP PPKn MTs Kabupaten Ponorogo bahwa guru-guru PPKn perlu dipandu dalam menyusun modul PPKn, karena selama ini belum pernah menyusun modul sehingga perlunya untuk di dampingi dalam menyusun modul PPKn MTs. Berdasarkan permasalahan tersebut maka dilaksanakannya suatu kegiatan pelatihan pembuatan/penyusunan bahan ajar berupa modul. Selain itu, disediakan kelas pendampingan pembuatan bahan ajar berupa modul sampai mampu memahami tata cara pembuatan modul hingga penyusunan modulnya. 
Metode yang digunakan dalam kegiatan ini meliputi pelatihan dan praktik dalam membuat bahan ajar berupa modul, ceramah dan tanya jawab. Saat disediakan kelas pendampingan, peserta pelatihan diberikan kebebasan seluas-luasnya untuk bertanya terkait penyusunan modul sampai mampu terselesaikannya modul tersebut. Setelah kegiatan selesai, modul tersebut bisa diterapkan guru dalam kegiatan pembelajaran di kelas sehingga siswa mampu belajar secara mandiri.

Adapun langkah-langkah dalam kegiatan ini sebagai berikut:

1. Memberikan pemahaman tentang modul dan cara membuat bahan ajar berupa modul kepada guru PPKn

2. Membagi setiap peserta pelatihan untuk praktik mengerjakan bahan ajar modul berdasarkan kelas yang diampu

3. Mendampingi guru dalam membuat/menyusun bahan ajar modul sampai terbentuknya karya guru berupa modul PPKn SMP/MTs.

\section{HASIL DAN PEMBAHASAN}

Kegiatan pengabdian masyarakat ini dilaksanakan satu kali di tahun 2018. Kegiatan ini dilaksanakan setiap hari kamis selama 3 kali pertemuan pada tanggal 22 Februari, 8 Maret, dan 22 Maret 2018. Peserta pengabdian masyarakat ini berjumlah 13 guru PPKn yang tergabung di dalam MGMP PPKn MTs se-Kabupaten Ponorogo. Tujuan dari kegiatan ini untuk memberikan pelatihan dan pendampingan kepada guru MGMP PPKn dalam membuat modul PPKn SMP/MTs.

Kegiatan ini dimulai pukul 08.00 sampai pukul 14.00. Kegiatan pertemuan pertama dilaksanakan di Aula MTs Negeri 3 Ponorogo pada tanggal 22 Februari 2018. Penyampaian materi oleh Ibu Ambiro Puji Asmaroini, M.Pd dan Bapak Ardhana Januar Mahardhani, M.KP. Adapun materi yang disampaikan tentang konsep bahan ajar, konsep modul, dan tata cara pembuatan modul PPKn SMP/MTs. Kegiatan hari pertama dapat dilihat berdasarkan gambar 5.1 berikut.

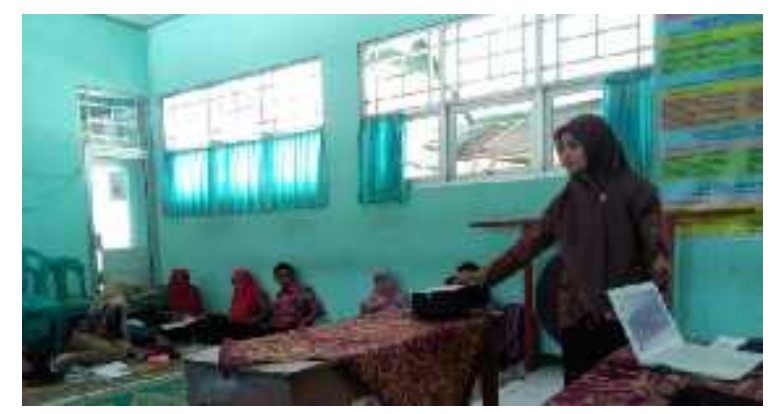

\section{Gambar 1 penyampaian materi tentang bahan ajar modul}

Pada gambar 5.1 tersebut materi telah disampaikan. Setelah itu, guru PPKn MGMP MTs diberikan arahan untuk mencoba mempelajari sistematika bahan ajar (modul) yang dicontohkan oleh pemateri. Kemudian, para guru secara langsung praktik menyusun bahan ajar (modul) PPKn SMP/MTs.

Kegiatan pertemuan kedua dilaksanakan pada tanggal 8 Maret 2018. Dilaksanakan di Laboratorium Microteaching Universitas Muhammadiyah Ponorogo. Pada pertemuan kedua ini, telah dilaksanakan pendampingan pembuatan bahan ajarr 
modul. Modul yang dikembangkan menggunakan model Degeng, untuk SMP/MTs kelas 7 dan 8. Kegiatan pendampingan pertemuan kedua dapat dilihat berdasarkan gambar 5.3 berikut.

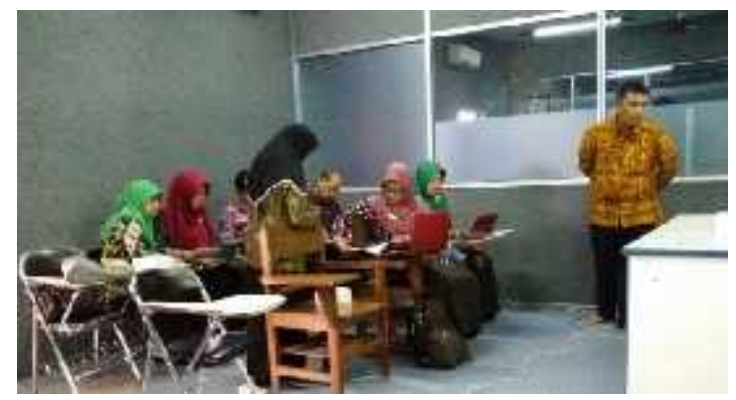

\section{Gambar 2 Pendampingan penyusunan bahan ajar modul}

Kegiatan pertemuan ketiga atau terakhir dilaksanakan tanggal 22 Maret 2018. Dilaksanakan di Laboratorium Microteaching Universitas Muhammadiyah Ponorogo. Kegiatan pertemuan terakhir ini merupakan pendampingan terakhir dalam penyusunan bahan ajar modul. Kegiatan pendampingan yabg terakhir dapat dilihat berdasarkan gambar 5.4 berikut.

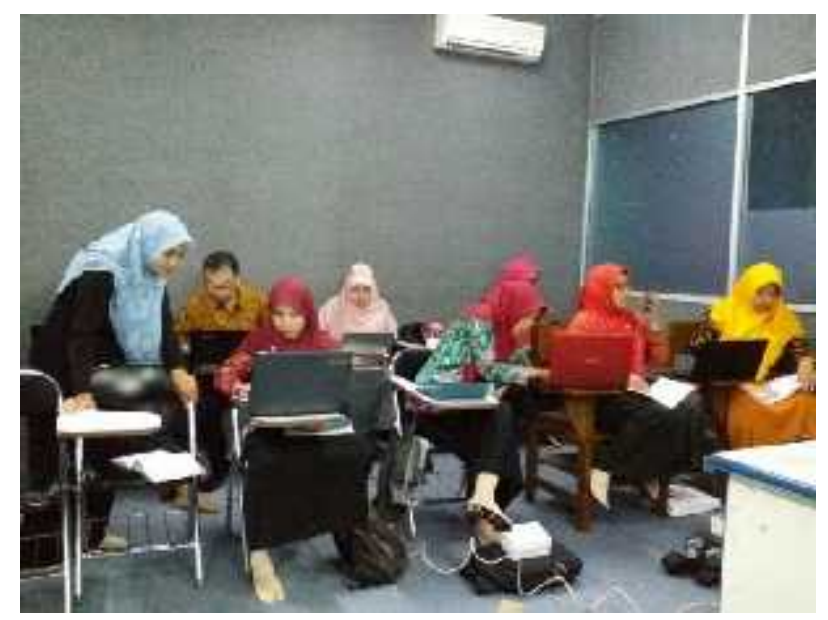

\section{Gambar 3 Pendampingan penyusunan bahan ajar modul terakhir}

Pada pertemuan terakhir dari 13 peserta awal menghasilkan produk berupa bahan ajar modul PPKn SMP/MTs kelas 7 dan 8. 12 peserta mampu menyelesaikan 1 BAB modul, sedangkan 1 peserta lain mampu menyelesaikan 1 buku bahan ajar kelas 8 SMP/MTs oleh Ibu Sri Harmanti, S.Pd dari MTs Negeri 3 Ponorogo. Saat ini buku tersebut sedang proses revisi dan ISBN.

\section{SIMPULAN}

Setelah kegiatan ini berakhir guru-guru PPKn di MTs Kabupaten Ponorogo mampu: 1) Memahami materi tentang modul, 2) Memahami tata cara penyusunan modul, dan 3) Menyusun/Membuat modul PPKn untuk SMP/MTs. Dari 13 peserta menghasilkan modul PPKn untuk SMP/MTs kelas 7 dan 8. 12 peserta mampu menyelesaikan 1 bab modul, sedangkan 1 peserta lain mampu menyelesaikan 1 modul kelas 8 SMP/MTs oleh Ibu Sri Harmanti, S.Pd dari MTs Negeri 3 Ponorogo. Saat ini buku tersebut sedang proses revisi dan pengurusan ISBN. 


\section{DAFTAR RUJUKAN}

Direktorat Jendral Peningkatan Mutu. 2010. Prosedur Operasional Standar Penyelenggaraan KKG dan MGMP. Kementerian Pendidikan Nasional

Direktorat Profesi Pendidik. 2008. Standar Pengembangan Kelompok Kerja Guru (KKG) Musyawarah Guru Mata Pelajaran (MGMP). Departemen Pendidikan Nasional Repubublik Indonesia 
46 J-Abdipamas, Vol. 3, No. 2 Oktober, 2019 